\title{
Outbreak of pertussis in Basra, Iraq
}

K.A. Al-Bargish'

$$
\text { كاظية عند النشاهوق في البصرة، بالعراق }
$$

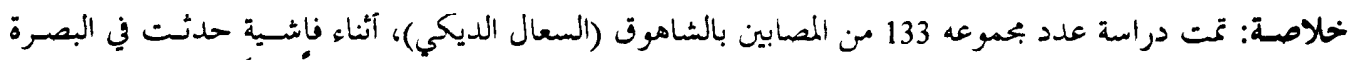

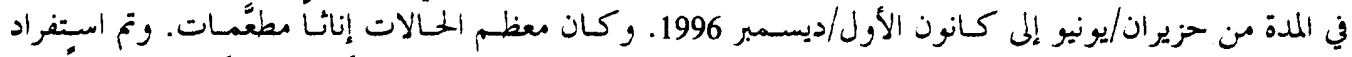

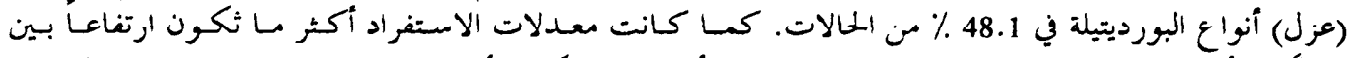

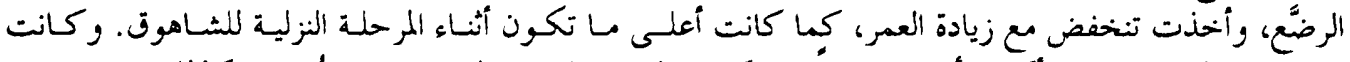

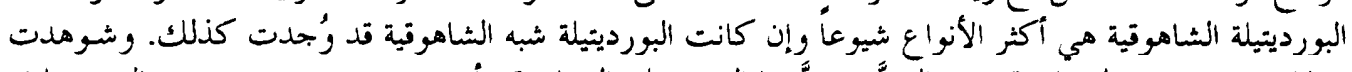

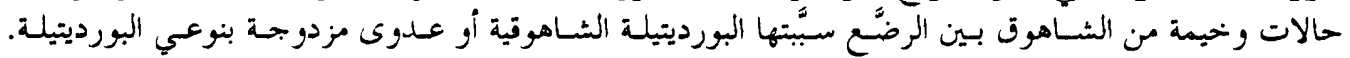

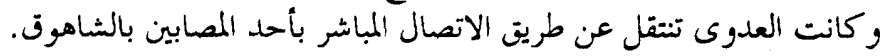

ABSTRACT A total of 133 pertussis cases were studied during an outbreak in Basra from June to December 1996. Most were females and were immunized. Bordetella spp. was isolated in $48.1 \%$ of the cases. The isolation rate was highest among infants and decreased with increasing age, and was highest during the catarrhal stage. $B$. pertussis was the most common species; however, $B$. parapertussis infection did occur. There were some severe cases of pertussis among infants caused mainly by $B$. pertussis and dual Bordetella infection. Infection was transmitted by close contact with a pertussis case.

\section{Flambée épidémique de coqueluche à Bassora (Iraq)}

RESUME Au total, 133 cas de coqueluche ont été étudiés pendant une flar.bée épidémique à Bassora de juin à décembre 1996. La plupart étaient des sujets de sexe féminin et avaient été vaccinés. Bordetella spp. a été isolé dans $48,1 \%$ des cas. Le taux d'isolement était le plus élevé chez les nourrissons et diminuait avec l'âge; il était le plus élevé à la phase catarrhale. $B$. pertussis était l'espèce la plus courante. Cependant, l'infection à $B$. parapertussis s'est produite. II y a eu quelques cas de coqueluche grave chez les nouveau-nés causés principalement par $B$. pertussis et une double infection à $B$. pertussis et $B$. parapertussis. L'infection était transmise par contact proche avec un cas de coqueluche.

'Department of Microbiology, College of Medicine, University of Basra, Basra, Iraq.

Received: 21/10/97; accepted: 01/11/98 


\section{Introduction}

Routine mass immunization of infants and children against pertussis has markedly decreased the morbidity and mortality attributed to this disease throughout the world [1]. However, without natural reinfection with Bordetella pertussis or repeated booster vaccinations, older children and adults are susceptible to the disease if cxposed and mothers provide little if any passive protection to young infants [2,3].

The incidence of pertussis is high in developing and industrialized countries where vaccine coverage is low [4]. In the United States (US), lax implementation of vaccination policy is partially responsible for the rise in annual pertussis incidence to 1.2 cases per 100000 from 1980 to 1989 and epidemic pertussis in many states in the US in 1989-1990 and 1993 [5].

Immunity to pertussis wanes after 5-10 years. However, whole cell vaccine boosters are not recommended for people older than 7 years because of conccrns about adverse reactions $[1,6]$. The acellular pertussis vaccine provokes fewer local and systemic reactions in children than the whole cell vaccine and this may also be true for the adult vaccine $[6,7]$.

$B$. pertussis is the sole cause of epidemic pertussis and the usual cause of sporadic pertussis $[2,8]$. B. parapertussis is an occasional cause of pertussis accounting for less than $5 \%$ of isolates of Bordetella species [2]. However, one study has suggested that B. parapertussis causes $22 \%$ of pertussis cases [9]. In addition, some European studies have suggested that this organism causes $20 \%-30 \%$ of cases of pertussis syndrome [10].

Nasopharyngeal cultures are positive for Bordetella during the catarrhal stage and early paroxysmal stage of the disease, but are less likely to be positive in partially immune individuals and those who have received amoxicillin or erythromycin [2]. As a rule, Bordetella spp. can be isolated in $70 \%-90 \%$ of cases in the catarrhal stage, in $40 \%-60 \%$ in the second week; and in only a negligible number of cases after 4-5 weeks [11].

There are few studies regarding the extent of the disease in Iraq. Therefore, this study was conducted during an outbreak of pertussis in Basra in 1996 in order to provide baseline data for laboratory diagnosis and the extent of pertussis in Iraq. The objectives of the study were to estimate the distribution of pertussis cases among those infected and to determine the isolation rate of Bordetella spp. from patients with clinical pertussis in relation to age, sex, duration and severity of illness and other factors.

\section{Materials and methods}

\section{Study design and patients}

The study was conducted in Basra southern Iraq and involved patients with whooping cough (pertussis). It was conducted from June 1996 to December 1996. During this period there was an outbreak of pertussis in the population in various age groups, but primarily among infants and adults.

Diagnosis of each case was based on the following clinical criteria $[2,12]$ : patients with a cough lasting at least 2 weeks with one of the following:

- paroxysmal cough

- inspiratory whoop

- post-tussive vomiting

- early diagnosis of an epidemiological link to a pertussis case.

Samples from any case with a clinical diagnosis of pertussis were sent to the laboratory of the Department of Microbiology, 
College of Medicine Teaching Hospital. The patients were referred from outpatient clinics or were inpatients at the Paediatric Hospital and Teaching Hospital in Basra or were from private clinics. For each patient, a complete form indicating age, sex, duration of illness, antibiotic used, immunization status, history of close contact with a pertussis case within or external to the family and hospital admission during the illness period was collected. Accordingly, 133 patients were included in the study. However, this number may represent only a small portion of the outbreak as there were many patients during the outbreak who were not included in the study.

\section{Laboratory diagnosis}

Posterior nasopharyngeal swabs were taken in the laboratory and immediately inoculated onto Bordet-Gengou medium. The medium was prepared each week and contained $10 \%$ blood and $0.04 \mathrm{mg} / \mathrm{ml}$ cephalexin. The cultures were incubated at $37^{\circ} \mathrm{C}$ in humidified sealed jars and examined daily for 7 days. Colonies with the characteristics of Bordetella microorganisms were Gram-stained.
Two species of Bordetella were isolated and differentiated. B. pertussis appears as small colonies within 2-3 days; the colonies are citrate- and urease-negative and do not grow on MacConkey or peptone media. $B$. parapertussis grows as slightly larger colonies which appear in 1-2 days, are citrate- and urease-positive and grow on MacConkey and peptone media [8].

\section{Results}

A total of 133 patients presented with pertussis and $53(39.8 \%)$ were children under 5 years of age. Of the 53 children under 5 ycars, $10(18.9 \%)$ infants under 2 months of age were not immunized and only 5 $(19.4 \%)$ children aged more than 1 year had no pertussis immunization (Tables 1 and 3).

Table 1 shows the isolation rates of Bordetella spp. according to age. The incidence of pertussis was highest in infants $<1$ year $(26.3 \%)$, followed by adults aged 30 years and older $(22.6 \%)$. Children aged 5-9 years were not affected by the disease.

Bordetella spp. was isolated in 64 patients $(48.1 \%)$ with pertussis (Table 1$)$. The

Table 1 Isolation rates of Bordetella spp. among pertussis patients according to age

\begin{tabular}{lrrrrrrrr}
\hline $\begin{array}{l}\text { Age } \\
\text { (years) }\end{array}$ & \multicolumn{2}{c}{ Patients } & \multicolumn{2}{c}{$\begin{array}{c}\text { B. portussis } \\
\text { No. }\end{array}$} & \multicolumn{1}{c}{$\%$} & \multicolumn{1}{c}{ No. } & \multicolumn{1}{c}{$\begin{array}{c}\text { B. parapertussis } \\
\text { No. }\end{array}$} & \multicolumn{2}{c}{ Total } \\
\hline$<1$ & $35^{\mathrm{a}}$ & 26.3 & 18 & 51.4 & 12 & 34.3 & $27^{\mathrm{b}}$ & 77.1 \\
$1-4$ & 18 & 13.5 & 5 & 27.8 & 7 & 38.9 & 12 & 66.7 \\
$5-9$ & 0 & 0.0 & 0 & 0.0 & 0 & 0.0 & 0 & 0.0 \\
$10-19$ & 25 & 18.8 & 8 & 32.0 & 3 & 12.0 & 11 & 44.0 \\
$20-29$ & 25 & 18.8 & 6 & 24.0 & 0 & 0.0 & 6 & 24.0 \\
$30-$ & 30 & 22.6 & 5 & 16.7 & 3 & 10.0 & 8 & 26.7 \\
Total & 133 & 100.0 & 42 & 31.6 & 25 & 18.8 & 64 & 48.1 \\
\hline
\end{tabular}

${ }^{a} 16 / 35(45.7 \%)$ of infants with pertussis were admitted to hospital.

${ }^{\mathrm{b}}$ There were three infants with both $\mathrm{B}$. pertussis and $\mathrm{B}$. parapertussis infection. 
isolation rate was highest among infants $(77.1 \%)$. The rate decreased with increasing age. B. pertussis was isolated in 42 patients $(31.6 \%)$ with pertussis while $B$. parapertussis was isolated in 25 patients $(18.8 \%)$. This difference was statistically significant $\left(\chi^{2}=5.771, P=0.0163\right)$. B. pertussis was most frequently isolated in infants $(51.4 \%)$ and the isolation rate decreased with increasing age. The isolation

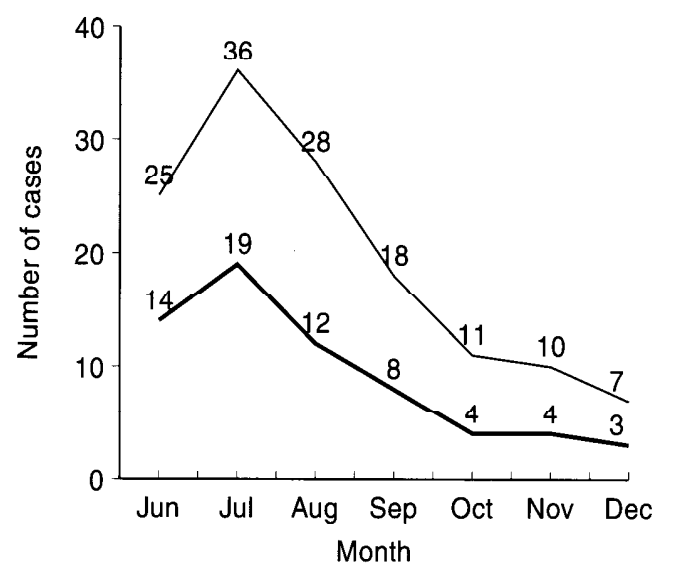

Total number of pertussis cases $=133$

Number of confirmed Bordetella infections $=64$

Figure 1 Distribution of pertussis cases during the outbreak in Basra (JuneDecember 1996) rate of $B$. parapertussis was also high in children under 5 years of age and decreased in older patients.

The outbreak of pertussis occurred in Basra from June to December 1996 (Figure 1). The number of pertussis cases and confirmed Bordetella infections were high in the first months, particularly in July. However, these cases represent only referred cases and there were many cases not included in our study. This was because of difficulties in referring patients to the laboratory, lack of cooperation from patients and the fact that many cases were diagnosed as pertussis with an epidemiological link to the outbreak and were treated in outpatient departments and health care centres without laboratory confirmation.

Patients were in various stages of illness when the nasopharyngeal swab was collected. Accordingly, the isolation rate of Bordetella was highest in week 1 (the catarrhal stage) of the illness $(62.9 \%)$, decreased in week $2(50.0 \%)$ and was lowest in week 3 and later (37.9\%) (Tablc 2). $B$. pertussis was isolated in $40 \%$ of pertussis cases during the catarrhal stage of the illness. However, B. parapertussis was also isolated in week $1(22.9 \%)$ and week 2 $(30.0 \%)$ of the illness. B. pertussis infection was isolated in $34.5 \%$ of patients in week 3 .

Table 2 Isolation rate of Bordetella spp. according to duration of illness at the time of nasopharyngeal swab collection

\begin{tabular}{lcrrrrrr}
\hline Duration of illness & $\begin{array}{c}\text { Pationts } \\
\text { No. }\end{array}$ & \multicolumn{2}{c}{ B. pertussis } & \multicolumn{2}{c}{ B. parapcrtussis } & \multicolumn{2}{c}{ Total } \\
& No. & $\%$ & No. & $\%$ & No. & $\%$ \\
\hline Week 1 & 35 & 14 & 40.0 & 8 & 22.9 & 22 & 62.9 \\
Week 2 & 40 & 8 & 20.0 & 12 & 30.0 & 20 & 50.0 \\
Week 3 & 58 & 20 & 34.5 & 5 & 8.6 & $22^{\text {a }}$ & 37.9 \\
\hline
\end{tabular}

${ }^{2}$ There were three patients with both $\mathrm{B}$. pertussis and $\mathrm{B}$. parapertussis infection. 
Table 3 Features of patients with pertussis and those with confirmed Bordetella spp. infection

\begin{tabular}{|c|c|c|c|c|c|c|c|c|c|}
\hline \multirow[t]{2}{*}{ Pertussis cases } & \multicolumn{2}{|c|}{ Patients } & \multirow[t]{2}{*}{$\begin{array}{l}\text { Male/ } \\
\text { female } \\
\text { ratio }\end{array}$} & \multicolumn{2}{|c|}{$\begin{array}{c}\text { Close contact } \\
\text { with } \\
\text { pertussis case }\end{array}$} & \multicolumn{2}{|c|}{ Immunization } & \multicolumn{2}{|c|}{$\begin{array}{l}\text { Erythromycin } \\
\text { treatment }\end{array}$} \\
\hline & No. & $\%$ & & No. & $\%$ & No. & $\%$ & No. & $\%$ \\
\hline $\begin{array}{l}\text { Pertussis cases } \\
\text { with Bordetella spp. } \\
\text { isolation }\end{array}$ & 64 & 100.0 & $1: 2.4$ & 48 & 75.0 & 49 & 76.6 & 16 & 25.0 \\
\hline B. pertussis & 39 & 60.9 & $1: 5.5$ & 26 & 66.7 & 34 & 87.2 & 11 & 28.2 \\
\hline B. parapertussis & 22 & 34.4 & $1: 0.7$ & 19 & 86.4 & 15 & 68.2 & 5 & 22.7 \\
\hline Dual infection & 3 & 4.7 & $0: 3$ & 3 & 100.0 & 0 & 0.0 & 0 & 0.0 \\
\hline $\begin{array}{l}\text { Pertussis cases } \\
\text { without Bordetella } \\
\text { spp. isolation }\end{array}$ & 69 & - & $1: 3.3$ & 38 & 55.1 & 46 & 66.7 & 15 & 21.7 \\
\hline Total pertussis cases & 133 & - & $1: 2.8$ & 86 & 64.7 & $95^{a}$ & 71.4 & 31 & 23.3 \\
\hline
\end{tabular}

${ }^{a} 48 / 53(90.6 \%)$ of children under 5 years had pertussis immunization.

Table 3 shows some features of patients and those with confirmcd Bordetella infection. The malc:female ratio for pertussis cases was $2: 8$ and $71.4 \%$ had been immunized. There were 64 bacteriologically proven pertussis cases. $B$. pertussis was the most common isolate and comprised 39 of the 64 cases $(60.9 \%)$, while $B$. parapertussis comprised 22 of the 64 cases $(34.4 \%)$ (Table 3). Both $B$. pertussis and $B$. parapertussis were isolated in three patients $(4.7 \%)$ with severe pertussis which necessitated hospitalization. These three patients were female infants under 2 months of age with no pertussis immunization: they presented with severe. prolonged cough. Most of the patients in whom Bordetella infection was confirmed were females, particularly with $B$. pertussis infections: the male:female ratio was $1: 5.5$ (Table 3).

Most of pertussis cases were mild but patients with severe pertussis were admitted to the hospital. All of the patients ad-
Table 4 Hospitalization rates for infants with demonstrated Bordetella spp. infection

\begin{tabular}{lccc}
\hline Infection & Pationts & \multicolumn{2}{c}{$\begin{array}{c}\text { Hospital } \\
\text { admission }\end{array}$} \\
& No. & No. & $\%$ \\
\hline B. pertussis & 15 & 7 & 46.7 \\
B. parapertussis & 9 & 2 & 22.2 \\
Dual infection & 3 & 3 & 100.0 \\
Total & 27 & 12 & $44.4^{a}$
\end{tabular}

${ }^{a} 12 / 16(75.0 \%)$ of hospitalized infants had Bordetella spp. infections.

mitted were infants under 1 year of age. A total of 16 out of 35 infants $(45.7 \%)$ with pcrtussis werc admitted to hospital (Table $1)$ and 12 of these 16 infants $(75.0 \%)$ had Bordetella infections (Table 4). Also, $46.7 \%$ of infants with $B$. pertussis and $22.2 \%$ with $B$. parapertussis infection were admitted. This difference was not statistically significant $\left(\chi^{2}=3.68 . P=0.055\right)$. All 
infants with both B. pertussis and B. parapertussis infections were admitted to hospital.

In all, $87.2 \%$ of $B$. pertussis isolates were recovered from immunized patients (Table 3). However, there were 10 infants under 2 months of age with no immunization, 3 of whom were infected with both $B$. pertussis and $B$. parapertussis and 7 had $B$. parapertussis infection. In addition, 5 out of 53 children (9.4\%) over 1 year of age had no immunization but they had taken erythromycin for more than 1 week before swab collection and showed negative culture for Bordetella spp. However, $25.0 \%$ of patients with confirmed Bordetella infection had taken erythromycin for less than 3 days and the results of culture were not affected (Table 3).

With regard to contact with pertussis cases, $75.0 \%$ of patients with confirmed Bordetella infection had had previous close contact with pertussis cases within the home, family or, less commonly, outside the home (Table 3).

\section{Discussion}

Pertussis remains a major problem in Arab countrics during infancy and carly childhood and has a high case fatality rate among infants who develop the disease in the first 6 months of life [13]. In the Eastern Mediterranean Region of the WHO the annual incidence rate between 1974 and 1982 varied from 26.2 to 50.2 per 100000 population [13]. However, the incidence has decreased to 0.0 to 6.9 per 100000 population in recent years [14].

In the present study, the highest incidence of pertussis was among infants and adults while young children aged 1-4 years had lower incidence rates. Children aged 5-9 years were not affected by the disease.
The proportion of those affected increased for adolescents and adults. Similar age patterns were observed in the US during a 1993 epidemic; $44 \%$ were infants, $21 \%$ were aged $1-4$ years, $11 \%$ were aged 5-9 years and $24 \%$ were 12 years of age or older [3]. In contrast, in the pre-vaccine era the peak incidence of pertussis was among children 1-5 years of age and infants younger than 1 year accounted for less than $15 \%$ of cases $[2,5]$.

In this study, pertussis immunization coverage for children under 5 years of age was approximatcly $90 \%$. This high immunization coverage concurs with the immunization rate recorded in 1995 in Iraq. The reported incidence of pertussis in that year was 2.4 per 100000 population [14], but this incidence rate might have been underestimated because of poor reporting.

Pertussis in adolescents and adults is mild or atypical and is difficult to diagnose unless the doctor is alerted to it as he/she may not hear the characteristic cough, which may be the only symptom [15-18]. In our study adolescents and adults represented a high percentage of patients with pertussis, which was usually mild.

The incidence of pertussis is still higher in Iraq than in other countries of the Eastern Mediterranean Region of WHO. There were more than 5000 reported pertussis cases in Iraq during 1990-1993 [19]. The high incidence of pertussis found in our study, despite high vaccination coverage, can be attributed to three important factors. First, the disease primarily affected infants, most of whom were under 6 months of age and had not yet received the full benefit of immunization $[2,6]$. Immunization protection was obvious among children 5-9 years of age who had taken four or five doses of the diphtheria, pertussis and tetanus (DPT) immunization. Very few of these children contracted the disease. Second, the disease 
was common among the adolescent and adult population. This could be attributed to the fact that the effectiveness of the vaccine diminishes after 5-10 years $[1,6,12,16]$. Therefore, booster doses of acellular pertussis vaccine are recommended for adolescents and adults [2,7,16]. Third and most importantly, poor nutrition, especially among infants, as a result of the sanctions on Iraq has led to severe malnutrition in more than $12 \%$ of children under 5 years of age [20].

Improvements in nutrition and social conditions are partially responsible for the decline in the incidence of pertussis in developing and industrialized countries [11]. A recent study in London emphasized the importance of an adequate nutrition level in combating pertussis in developing countries where pertussis remains a lethal disease in children because of immunodeficiency linked to severe malnutrition [21].

One of the main purposes of this study was to confirm the infection by isolation of Bordetella spp. from the patients. All current methods for confirmation of infection with Bordetella spp. have limitations in sensitivity, specificity or practicality [2]. Isolation of the bacteria in culture is the gold standard and if careful allention is paid to specimen collection, transport and isolation techniques, is a more sensitive and specific method of diagnosis than direct fluorescent antibody testing of nasopharyngeal secretions [2]. This was taken into consideration in our study in order to obtain the best possible culture results.

From June to December 1996, Bordetella spp. was isolated in $48.1 \%$ of patients with pertussis. It has been suggested that during this period an outbreak of pertussis occurred. The isolation rate of Bordetella spp. was high among infants and decreased with increasing age and a low rate of isolation was seen among adults. The isolation of $B$. pertussis was higher than $B$. parapertussis which is the most common cause of epidemic pertussis $[2,11,12]$. However, $B$. parapertussis infection was nearly as common as $B$. pertussis infection in children under 5 years of age. In addition, overall $39 \%$ of confirmed Bordetella infections were caused by $B$. parapertussis. This is a very high rate of $B$. parapertussis infection in comparison to previous observations in which this species caused $20 \%-30 \%$ of cases of pertussis $[9,10]$. Thus, the results indicate that an epidemic of $B$. pertussis and $B$. parapertussis occurred in Basra. In addition, dual Bordetella infection was seen in $4.7 \%$ of patients with confirmed Bordetella infection and caused severe pertussis, especially in infants. B. pertussis was more frequently isolated in female patients, which is in contrast to most other febrile diseases [2,11,22].

Pertussis cases tended to be mild among the adolescent and adult population, but the disease tended to be severe in infants. About half of the infants presented with severe pertussis and were admitted to hospital. In most of them (75\%) Bordetella infection was confirmed; this pattern has been observed previously [22]. The incidence of hospitalization emphasized the seriousness of the illness in infants. In infants with confirmed Bordetella infection, the hospitalization rate was high for $B$. pertussis infection because of the seriousness of the illness caused by this organism. However, the highest rate of hospitalization occurred in infants with both $B$. pertussis and $B$. parapertussis infection, which reflects the severity of the illness caused in infants under 2 months with no immunization. This pattern has also been observed previously [9,23]. Therefore, pertussis immunization is recommended at birth, month 1 
and month 2 to reduce the risk of severe infection $[1,2]$.

$B$. parapertussis usually causes mild illness $[2,11]$, but severe cases with $B$. parapertussis infection may actually represent dual infections with $B$. pertussis $[9,10]$. However, in this study B. parapertussis caused severe illness which required hospitalization. Approximately $22 \%$ of infants with confirmed B. parapertussis infection were admitted to hospital because of the seriousness of the disease.

The majority of patients with confirmed Bordetella infection had previous close contact with a pertussis case, generally a household contact or less commonly other close contact. This indicates that the infection is transmitted from person to person through close contact $[2,11,24]$.

Although most of the patients with confirmed Bordetella infection were immunized, non-immunized female infants under 2 months of age had higher isolation rates of Bordetella spp. [2,25]. In a few non-immunized children, Bordetella infection was not found because they had taken erythromycin for more than 1 week before culture. Therefore, immunization and erythromycin intake partially affected the isolation rate of Bordetella spp.

\section{References}

1. Pertussis surveillance - United States, 1986-1988. Mortality and morbidity weekly reports, 1990, 39:57-65.

2. Long SS. Pertussis. In: Nelson WE et al. eds. Nelson textbook of pediatrics. Philadelphia, WB Saunders Company, 1996:779-84.

3. Resurgence of pertussis - United States, 1993. Morbidity and mortality weekly reports, 1993, 42:952-3.

4. Binkin NJ et al. Epidemiology of pertussis in a developed country with low vaccination coverago: the Italian experience. Pediatric infectious disease journal, 1992, 11:653-61.

5. American Academy of Pediatrics. Pertussis. In: Peter G, ed. 1994 Red Book: report of the Committee on Infectious Diseases, 23rd ed. Elk Grove Village, Illinois, American Academy of Pediatrics, 1994:355-67.

6. Morgan $\mathrm{CM}$ et al. Comparison of acellular and whole cell pertussis component DPT vaccines. American journal of diseases of children, 1990, 144:41-5.
7. Edwards $\mathrm{KM}$ et al. Adult immunization with acellular pertussis vaccine. Journal of the American Medical Association, 1993, 269:53-6.

8. Bordelella. In: Holt JG et al. eds. Bergey's manual of determinative bacteriology, 9th ed. Baltimore, Williams and Wilkins, 1996:78.

9. Linnemann CC, Perry EB. Bordetella parapertussis: recent experience and a review of the literature. American journal of diseases of children, 1977, 131: 5603.

10. Borska K, Simkovicova M. Studies on the circulation of $B$. pertussis and $B$. parapertussis in populations of children. Journal of hygiene, epidemiology, microbiology and immunology, 1972, 16:15972.

11. Smith JWG. Whooping cough. In: Topley WWC, ed. Topley and Wilson's principles of bacteriology, virology and immunity, 7th ed. Baltimore, Willams and Wilkins, 1984:392-401. 
12. Matter HC, Schmidt-Schlapter G, Zimmermann $H$. Erfassung einer keuchhusten-epidemic 1994/95 in der Schweiz durch das Sentinella-Meldesystem. Sentinella-Arbeitsgemeinschaft. [Monitoring of a whooping cough epidemic 1994-95 in Switzerland using the sentinel notification system. Sentinella Registry]. Schweizerische-medizinische wochenschrift, 1996, 126(34):1423-32.

13. Vital statistics and causes of death. World health statistics annual. Geneva, World Health Organization, 1982.

14. Regional demographic and socioeconomic data. Eastern Mediterranean health journal, 1996, 2(2):347-53.

15. Cherry JD, Baraff LJ, Hewlett E. The past, present and future of pertussis. The role of adults in epidemiology and future control. Western journal of medicine, 1989 , 150:319-28.

16. Mink CAM, Sirota NM, Nugent S. Outbreak of pertussis in a fully immunized adolescent and adult population. Archives of pediatric and adolescent medicine, 1994, 148:153-7.

17. Deville JG et al. Frequency of unrecognized Bordetella pertussis infections in adults. Clinical infectious disease, 1995, 21(3):639-41.

18. Cattaneo LA et al. The seroepidemiology of Bordetella pertussis infections: a study of persons ages 1-65 years. Journal of infectious diseases, 1996, 173(5):12569.

19. Communicable diseases. Annual and quarterly incidence of pertussis cases 1990-1994 in the Eastern Mediterranean Region. EMR epidemiological bulletin, 1994, 24:30.

20. Court C. Iraq sanctions lead to half a million child deaths. British medical journal, 1995, 311(7019):1523.

21. Duncan CJ, Duncan SR, Scott S. Whooping cough epidemics in London, 1701812: infection dynamics, seasonal forcing and the effects of malnutrition. Proceedings of the Royal Society of London. Series B: biological sciences, 1996, 263(1369):445 50.

22. Diagnosis of whooping cough: comparison of serological tests with isolation of Bordetella pertussis. A combined Scottish study. British medical journal, 1970, 4:637-9. 